\title{
PENGARUH SIKAP, MOTIVASI, DAN KETERAMPILAN BIDAN TERHADAP PENERAPAN METODE ASUHAN PERSALINAN NORMAL (APN) DI PRAKTIK MANDIRI BIDAN KOTA TERNATE
}

\author{
THE INFLUENCE OF MIDWIVES ATTITUDES, MOTIVATIONS, AND \\ SKILLS ON THE APPLICATION OF THE NORMAL DELIVERY CARE \\ METHOD (APN) IN THE INDEPENDENT PRACTICE MIDWIFE OF \\ TERNATE CITY
}

Eni Sulastri, Sri Linda

Jurusan Kebidanan Poltekkes Kemenkes Ternate

Korespondensi: enimuhfi2013@gmail.com

\begin{abstract}
Normal delivery care is carried out to maintain survival and provide a high degree of health for the mother and her baby, through integrated and complete efforts but with minimal interventions so that the principle of safety and service quality can be maintained at the desired level (optimal). Safe labor is needed because labor is a normal process and a healthy event. However, the potential for life-threatening complications will always be there, so the midwife must closely observe the mother and baby throughout the birth. Also, all birth attendants must have the knowledge, skills, and tools to provide safe and clean assistance and pay attention to the surrounding environment. Midwives can also be one of the factors that play a role in the normal delivery service process, the competence possessed by midwives in assisting childbirth is not necessarily the same as implementing a normal delivery care service consisting of 60 steps. the service. This study aims to determine the effect of midwives' attitudes, motivations, and skills on the application of the normal delivery care method (APN). This study is a quasi-experimental using a one-group design pattern with measurements of pre-test and post-test (one group pretest-posttest design).
\end{abstract}

Keywords: Midwives, Normal Childbirth Care

\begin{abstract}
ABSTRAK
Asuhan persalinan normal dilakukan dengan tujuan menjaga kelangsungan hidup dan memberikan derajat kesehatan yang tinggi bagi ibu dan bayinya, melalui upaya yang terintegrasi dan lengkap tetapi dengan intervensi yang seminimal mungkin agar prinsip keamanan dan kualitas pelayanan dapat terjaga pada tingkat yang di inginkan (optimal). Persalinan yang aman memang sangat dibutuhkan karena persalinan merupakan proses yang normal serta suatu kejadian yang sehat. Akan tetapi potensi komplikasi yang mengancam nyawa juga akan selalu ada, sehingga bidan harus mengamati dengan ketat ibu dan bayinya sepanjang kelahiran. Selain itu, semua penolong persalinan harus mempunyai bekal pengetahuan, keterampilan, dan alat untuk memberikan pertolongan yang aman dan bersih, serta memperhatikan lingkungan sekitar. Bidan juga dapat
\end{abstract}


menjadi salah satu faktor yang berperan dalam proses pelayanan persalinan normal, kompetensi yang dimiliki oleh bidan dalam menolong persalinan belum tentu sama untuk menerapkan pelayanan asuhan persalinan normal yang terdiri dari 60 langkah APN ada yang menggunakan standar pelayanan dan ada yang belum sepenuhnya menerapkan standar pelayanan tersebut. Penelitian ini bertujuan mengetahui pengaruh sikap, motivasi, dan keterampilan bidan terhadap penerapan metode asuhan persalinan normal (APN). Penelitian ini merupakan eksperimen semu (Quasy Experimental) menggunakan pola rancangan satu kelompok dengan pengukuran pre test dan post test (one group pretest posttest design).

\section{Kata kunci : Bidan, Asuhan Persalinan Normal}

\section{PENDAHULUAN}

Salah satu upaya yang dilakukan Departemen Kesehatan dalam mempercepat penurunan angka kematian ibu (AKI) adalah meningkatkan pengetahuan dan ketrampilan petugas kesehatan khususnya bidan didalam menolong persalinan. Asuhan Persalinan Normal (APN) dengan paradigma baru yaitu dari sikap menunggu terjadinya dan kemudian menangani komplikasi, menjadi mencegah komplikasi yang mungkin terjadi dan diharapkan dapat memberikan kontribusi dalam penurunan angka kematian ibu dan bayi baru lahir. Tingkat keterampilan bidan dan sarana kesehatan sangat terbatas, maka paradigma aktif menjadi sangat strategis bila dapat diterapkan pada tingkat tersebut. Berbagai faktor yang terkait dengan resiko terjadinya komplikasi yang berhubungan dengan kehamilan dan cara pencegahannya telah diketahui, namun demikian jumlah kematian ibu dan bayi masih tetap tinggi (Buku Acuan Pelatihan Klinik Asuhan Persalinan Normal. 2008).

Perhatian terhadap peristiwa kehamilan dan persalinan sangatlah penting. Untuk mempercepat penurunan AKI, maka setiap persalinan harus didampingi oleh tenaga kesehatan serta memberikan pelayanan kesehatan ibu dan anak (KIA) yang berkualitas, menyeluruh, dan terpadu. Hal itu diharapkan dapat meningkatkan cakupan pelayanan yang pada gilirannya akan menurunkan angka kematian ibu. Kira-kira 90\% kematian ibu terjadi saat persalinan dan sekitar 95\% penyebab kematian ibu adalah komplikasi obstetri yang sering tidak dapat diperkirakan sebelumnya (Wiknjosastro, H. 2017). 
Persalinan yang aman memang sangat dibutuhkan karena persalinan merupakan proses yang normal serta suatu kejadian yang sehat. Akan tetapi potensi komplikasi yang mengancam nyawa juga akan selalu ada, sehingga bidan harus mengamati dengan ketat ibu dan bayinya sepanjang kelahiran. Selain itu, semua penolong persalinan harus mempunyai bekal pengetahuan, keterampilan, dan alat untuk memberikan pertolongan yang aman dan bersih, serta memperhatikan lingkungan sekitar. Dalam hal ini, pertolongan persalinan yang menggunakan prinsip asuhan persalinan normal tersebut dapat menekan angka kematian ibu 40-45 per 100.000 kelahiran hidup. Tenaga kesehatan yang memberikan pelayanan obstetri dan neonatal, khususnya bidan harus mampu dan trampil memberikan pelayanan sesuai dengan standar yang ditetapkan untuk menurunkan maupun mencegah angka kematian ibu dan bayi (Wiknjosastro, H. 2017).

Penyebab langsung kematian maternal yang paling umum di Indonesia adalah perdarahan $28 \%$, eklapmsia $24 \%$, infeksi $11 \%$, partus lama $5 \%$ dan abortus $5 \%$. Sedangkan penyebab kematian bayi baru lahir yaitu
Berat Badan Lahir Rendah (BBLR) $29 \%$, asfiksia $27 \%$, tetanus neonatorum $10 \%$, masalah pemberian makan $10 \%$, gangguan hematologik $6,5 \%$, infeksi 5\% dan lain-lain 13\% (DepKes, 2016).

Berdasarkan studi pendahuluan, bidan yang mempunyai praktik mandiri bidan (PMB) di Kota Ternate sebesar $85 \%$ sudah mengikuti pelatihan APN. Walaupun cakupan sudah memenuhi target, namun untuk menjaga agar AKI dan AKB tidak semakin tinggi ini merupakan tanggung jawab semua jajaran kesehatan di Kota Ternate baik dokter, bidan puskesmas, bidan desa maupun praktik bidan mandiri. Hasil Riskesdas tahun 2018 bahwa proporsi penolong persalinan pada perempuan umur 10-54 tahun terdiri dari non tenaga kesehatan sebesar $6,7 \%$ sedangkan tenaga kesehatan sebesar $93,1 \%$, yang didalammnya terdapat penolong oleh bidan 62,7\%, dokter kandungan $28,9 \%$, dokter umum $1,2 \%$, dan perawat $0,3 \%$. Sedangkan tempat persalinannya terdiri dari Praktik Bidan Mandiri (PMB) 29\%, Poskesdes/Polindes 4\%, Puskesmas/Pustu/Pusling 12\%, Klinik 5\%, Praktik Dokter 1\%, Rumah Sakit Pemerintah 15\%, Rumah Sakit Swasta 18\%, dan Rumah 16\%. 
Hasil penelitian UNICEF tentang hubungan antara penolong yang terampil dan angka kematian ibu dan bayi bahwa kematian ibu akan menurun seiring dengan peningkatan keterampilan penolong persalinan. Sedangkan penyebab tidak langsung yang mendasarkan AKI dan AKB adalah faktor lingkungan, perilaku dan pelayanan kesehatan (Wiknjosastro, $\mathrm{H}$. 2017).

Bidan juga dapat menjadi salah satu faktor yang berperan dalam proses pelayanan persalinan normal kompetensi yang dimiliki oleh bidan dalam menolong persalinan belum tentu sama untuk menerapkan pelayanan asuhan persalinan normal yang terdiri dari 60 langkah APN ada yang menggunakan standar pelayanan dan ada yang belum sepenuhnya menerapkan standar pelayanan tersebut. Hal ini dipengaruhi oleh pengetahuan dan sikap dalam menolong persalinan (Saputra, L. 2014).

\section{METODE}

Penelitian ini termasuk penelitian observasional analitik dengan pendekatan Cross Sectional. Tempat penelitian di 5 (lima) Praktik Mandiri Bidan Kota Ternate. Waktu penelitian dilaksanakan pada bulan Oktober 2019.
Sampel dalam penelitian ini adalah 5 (lima) bidan yang memiliki Praktik Mandiri Bidan di Kota Ternate. Teknik pengambilan sampel dengan accidental sampling. Pengumpulan data dalam penelitian ini yaitu pengumpulan data primer menggunakan daftar checklist, daftar tilik dan lembar observasi berkaitan dengan asuhan persalinan normal. Data yang telah diperoleh kemudian dianalisis dengan analisis univariat untuk menggambarkan karakteristik responden. Setelah itu dilanjutkan dengan analisis bivariat untuk mengetahui kemaknaan dari pengaruh sikap, motivasi, dan keterampilan bidan di Praktik Mandiri Bidan terhadap penerapan metode asuhan persalinan normal (APN) dengan menggunakan uji Fisher,s Exact Test.

\section{HASIL DAN PEMBAHASAN}

Penelitian ini dilakukan terhadap penerapan metode asuhan persalinan normal (APN) dan didapatkan hasil sebagai berikut:

Tabel 1. Karakteristik subjek penelitian

\begin{tabular}{lll}
\hline $\begin{array}{c}\text { Usia } \\
\text { (tahun) }\end{array}$ & $\begin{array}{c}\text { Frekuensi } \\
(\mathbf{f})\end{array}$ & $\begin{array}{c}\text { Persentase } \\
(\boldsymbol{\%})\end{array}$ \\
\hline 38 & 1 & 20 \\
39 & 2 & 40 \\
40 & 2 & 40 \\
\hline Jumlah & 5 & 100 \\
$($ n) & & \\
\hline
\end{tabular}


Tabel 1 menggambarkan karakteristik subjek penelitian/responden pada usia 38-40 tahun.

Tabel 2. Pengaruh sikap bidan terhadap penerapan metode asuhan persalinan normal (APN) di Praktik Mandiri Bidan

\begin{tabular}{lccccl}
\hline \multirow{2}{*}{$\begin{array}{l}\text { Sikap } \\
\text { Bidan }\end{array}$} & \multicolumn{2}{c}{ Penerapan Metode APN } & Nilai \\
\cline { 2 - 5 } & $\begin{array}{c}\text { Sesuai } \\
\text { Standar }\end{array}$ & $\begin{array}{c}\text { Tidak } \\
\text { Sesuai } \\
\text { Standar }\end{array}$ & $\%$ & p $^{*}$ \\
\hline $\begin{array}{l}\text { Sikap } \\
\text { Positif }\end{array}$ & 1 & 20 & 3 & 60 & \\
\hline $\begin{array}{l}\text { Sikap } \\
\text { Negatif }\end{array}$ & 0 & 0 & 1 & 20 & 1,000 \\
\hline
\end{tabular}

Keterangan: *Uji Fisher's Exact Test

Tabel 2 menggambarkan bahwa bidan yang mempunyai sikap positif dengan menerapkan metode APN yang sesuai standar sebanyak 1 orang dan tidak sesuai standar sebesar 3 orang. Sedangkan yang mempunyai sikap negatif dengan menerapkan metode sesuai standar tidak ada dan tidak sesuai standar yaitu 1 orang.

Tabel 3. Pengaruh motivasi bidan terhadap penerapan metode asuhan persalinan normal (APN) di Praktik Mandiri Bidan

\begin{tabular}{lllllll}
\hline \multirow{2}{*}{$\begin{array}{l}\text { Motivasi } \\
\text { Bidan }\end{array}$} & \multicolumn{4}{l}{ Penerapan Metode APN } & \multicolumn{2}{c}{ Nilai } \\
\cline { 2 - 5 } & $\begin{array}{l}\text { Sesuai } \\
\text { Standar }\end{array}$ & $\%$ & $\begin{array}{l}\text { Tidak } \\
\text { Sesuai } \\
\text { Standar }\end{array}$ & $\%$ & $\mathbf{p}^{*}$ \\
\hline $\begin{array}{l}\text { Motivasi } \\
\text { Baik }\end{array}$ & 0 & 0 & 3 & 60 & \\
\hline $\begin{array}{l}\text { Motivasi } \\
\text { Kurang }\end{array}$ & 1 & 20 & 1 & 20 & 0,400 \\
\hline
\end{tabular}

Keterangan: *Uji Fisher's Exact Test
Tabel 3 menggambarkan bahwa bidan yang mempunyai motivasi baik dengan menerapkan metode APN yang sesuai standar tidak ada dan tidak sesuai standar sebesar 3 orang. Sedangkan yang mempunyai motivasi kurang dengan menerapkan metode sesuai standar dan tidak sesuai standar masingmasing yaitu 1 orang.

Tabel 4. Pengaruh keterampilan bidan terhadap penerapan metode asuhan persalinan normal (APN) di Praktik Mandiri Bidan

\begin{tabular}{lllllll}
\hline \multirow{2}{*}{$\begin{array}{l}\text { Keterampilan } \\
\text { Bidan }\end{array}$} & \multicolumn{3}{l}{ Penerapan Metode APN } & \multirow{2}{*}{ Nilai } \\
\cline { 2 - 5 } & $\begin{array}{l}\text { Sesuai } \\
\text { Standar }\end{array}$ & $\%$ & $\begin{array}{l}\text { Tidak } \\
\text { Sesuai } \\
\text { Standar }\end{array}$ & $\%$ & p $^{*}$ \\
\hline Trampil & 1 & 20 & 0 & 0 & 0 \\
\hline Tidak Trampil & 0 & 0 & 4 & 80 & 0,200 \\
\hline
\end{tabular}

Keterangan: *Uji Fisher's Exact Test

Tabel 4 menggambarkan bahwa bidan yang mempunyai keterampilan dengan menerapkan metode APN yang sesuai standar sebanyak 1 orang dan tidak sesuai standar sebesar 3 orang. Sedangkan yang mempunyai sikap negatif dengan menerapkan metode sesuai standar tidak ada dan tidak sesuai standar yaitu 1 orang.

Bidan merupakan ujung tombak terdepan dalam memberikan pelayanan persalinan dan mereka mempunyai kontribusi langsung terhadap kematian ibu dan bayi. Persalinan yang ditolong oleh bidan yang berkompeten dapat 
meningkatkan cakupan persalinan yang normal yaitu 90\%. Asuhan Persalinan Normal merupakan salah satu cara untuk menurunkan angka kematian ibu (AKI) dan angka kematian bayi (AKB) dimana fokus penerapan metode APN adalah untuk mencegah perdarahan post partum, asfiksia bayi baru lahir/hipotermi, infeksi dan partus lama (Soleh ES, 2018).

Sikap adalah perasaan, pikiran, dan kecenderungan seseorang yang kurang lebih bersifat permanen mengenai aspek-aspek tertentu dalam lingkungannya. Sikap terbagi atas sikap positif dan sikap negatif. Pada penelitian ini, sikap yang ditunjukkan oleh bidan yaitu sikap positif, akan tetapi tidak mempunyai pengaruh terhadap penerapan metode asuhan persalinan normal (APN) di Praktik Mandiri Bidan. Dari hasil uji Fisher Exact terdapat nilai $\mathrm{p}$ value $(\mathrm{p}=1,000)$, yang memberikan makna bahwa tidak terdapat pengaruh antara sikap bidan terhadap penerapan metode asuhan persalinan normal (APN) di Praktik Mandiri Bidan.

Hal ini sejalan dengan penelitian yang dilakukan oleh Darmawaty Mappa, 2007, bahwa meskipun sikap sebagian dipengaruhi oleh pengetahuan, namun belum tentu dengan pengetahuan yang baik seseorang memiliki sikap yang positif pula. Hal ini disebabkan karena proses adaptasi, sikap membutuhkan proses dan tahapan dalam penerimaan informasi seperti yang dikemukakan oleh Newcomb dalam Notoatmodjo (2003) bahwa sikap dapat terbentuk dari menerima informasi, merespon, menghargai dan bertanggung jawab terhadap informasi tersebut, namun proses penerimaan tersebut tergantung sejauh mana daya ingat dan pemahaman seseorang tentang apa yang disampaikan, selain itu sikap merupakan manifestasi yang tidak dapat langsung dilihat, tetapi hanya dapat ditafsirkan terlebih dahulu dari perilaku tertutup yang didapat dari stimulus atau rangsangan dari luar (Sarwono, Sarlito W. 2011).

Setiap aktivitas manusia pada dasarnya dilandasi oleh adanya dorongan untuk mencapai tujuan atau terpenuhi kebutuhannya yang disebut motivasi. Pada penelitian ini, motivasi yang ditunjukkan oleh bidan yaitu motivasi yang baik, akan tetapi tidak mempunyai pengaruh terhadap penerapan metode asuhan persalinan normal (APN) di Praktik Mandiri Bidan. Dari hasil uji Fisher Exact 
terdapat nilai $\mathrm{p}$ value $(\mathrm{p}=0,400)$, yang memberikan makna bahwa tidak terdapat pengaruh antara motivasi bidan terhadap penerapan metode asuhan persalinan normal (APN) di Praktik Mandiri Bidan.

Motivasi adalah dorongan dalam diri yang tercermin dalam perilaku. Timbulnya dorongan itu disebabkan oleh adanya insentif (rangsangan), atau stimulus yang harus diraih untuk memenuhi kebutuhannya, suatu kondisi yang berpengaruh untuk membangkitkan, mengarahkan dan memelihara perilaku yang berhubungan dengan pelaksanaan pekerjaan (Nafiah U, dkk. 2014).

Perilaku bidan dalam memberikan asuhan persalinan normal dipengaruhi oleh pengetahuan, motivasi diri, komunikasi, lingkungan, fasilitas/alat, peraturan tentang persalinan (protap), dan kondisi darurat pasien. Dalam penelitian ini, bidan tidak menerapkan asuhan persalinan dengan baik karena dipengaruhi lingkungan yang belum sesuai standar, alat/fasilitas yang belum sesuai standar. Sedangkan faktor yang memengaruhi bidan tidak dapat melakukan APN karena adanya kondisi dimana bidan sudah terbiasa dengan pemberian pelayanan yang tidak menerapkan metode APN, walaupun telah mengikuti pelatihan. Mereka mengungkapkan bahwa adanya asuhan persalinan normal dapat menurunkan angka kematian ibu karena pelayanan yang diberikan berupa asuhan sayang ibu dan memperhatikan pencegahan infeksi dalam penularan penyakit akan tetapi pada kenyataannya tidak dilaksanakan (Ismiyati, 2010).

Keterampilan adalah suatu kemampuan untuk menerjemahkan pengetahuan ke dalam praktik sehingga tercapai hasil kerja yang diinginkan. Pada penelitian ini, keterampilan yang ditunjukkan oleh bidan yaitu tidak trampil (tidak melaksanakan pertolongan sesuai 60 langkah APN) dan tidak menerapkan metode asuhan persalinan normal (APN) di Praktik Mandiri Bidan. Dari hasil uji Fisher Exact terdapat nilai $\mathrm{p}$ value $(\mathrm{p}=0,200)$, yang memberikan makna bahwa tidak terdapat pengaruh antara keterampilan bidan terhadap penerapan metode asuhan persalinan normal (APN) di Praktik Mandiri Bidan.

Penelitian Nuriana

(2008) bahwa pengetahuan berpengaruh terhadap pelaksanaan standar APN, karena bidan yang berpengetahuan baik akan dapat memberikan pelayanan yang 
baik pula dalam asuhan persalinan normal, sehingga pada akhirnya tujuan asuhan persalinan dapat dicapai dengan optimal.

Berdasarkan teori P2KP-KR (2009) yang menyatakan bahwa angka kematian ibu akan menurun seiring dengan peningkatan keterampilan penolong, dengan dasar ini pentingnya keterampilan penolong, peningkatan keterampilan itu melalui pelatihan Asuhan Persalinan Normal yang di ikuti oleh Bidan. Menurut penelitian Diana (2008) pelatihan APN berpengaruh terhadap pelaksanaan standar APN hal tersebut dikarenakan bila Bidan telah mengikuti pelatihan APN maka Bidan itu dapat melaksanakan APN dengan baik (Sari I, 2016). Akan tetapi, dalam penelitian ini bidan tidak menunjukkan keterampilannya dalam menolong persalinan sesuai standar APN, baik itu dari alat dan bahan maupun cara pertolongan persalinannya. Hal ini disebabkan karena kebiasaan yang telah dilakukan dalam waktu yang lama. Sesuai dengan teori perilaku yang mengatakan bahwa suatu tindakan atau perbuatan itu menjadi kebiasaan karena dilakukan secara berulang-ulang. Dampak dari tindakan yang berulangulang itu membuat tidakan itu menjadi tetap. Jadi dalam situasi apapun, orang pasti melakukan hal yang kurang lebih sama. Sehingga dengan kebiasaan yang rutin dan menetap itu membuat otak menjadi tidak aktif dalam jangka waktu lama.

Penelitian oleh Maimunah (2005) memperoleh hasil bahwa pelatihan APN dan pengetahuan bidan berpengaruh terhadap keterampilan bidan dalam menolong persalinan normal. Bidan yang pernah mengikuti palatihan APN akan semakin tinggi kemungkinan melaksanakan pertolongan persalinan normal dengan baik.

Salah satu tujuan pelatihan APN adalah memberikan pengetahuan dan keterampilan pelayanan persalinan normal dan penanganan awal penyulit beserta rujukan yang berkualitas dan sesuai dengan prosedur standar. Menurut Michael (2002), jika semua tenaga penolong persalinan dilatih agar mampu untuk mencegah atau deteksi dini komplikasi yang mungkin terjadi, menerapkan asuhan persalinan secara tepat guna dan tepat waktu, baik sebelum atau saat masalah terjadi, dan segera melakukan rujukan saat kondisi ibu masih optimal, maka ibu dan bayi baru lahir akan terhindar dari ancaman 
kesakitan dan kematian. Manfaat Asuhan Persalinan Normal dalam mencegah komplikasi persalinan dan nifas yang mungkin dapat membantu dalam upaya memahami proses persalinan agar menghindari intervensi yang tidak tepat dan komplikasi yang tidak perlu terjadi, karena jelas bahwa kehadiran tenaga terlatih saat persalinan akan mengurangi kemungkinan komplikasi dan kejadian fatal (Otto S, 2015).

\section{SIMPULAN}

Berdasarkan hasil dan pembahasan dapat disimpulkan bahwa bidan yang memiliki sikap, motivasi, dan keterampilan yang baik tidak menjamin bahwa dalam pelayanan pada ibu bersalin diterapkan metode asuhan persalinan normal. Hal ini dapat dilihat pada indikator hasil pengujian hipotesis yaitu tidak terdapat pengaruh sikap, motivasi dan keterampilan bidan terhadap penerapan metode asuhan persalinan normal (APN).

\section{UCAPAN TERIMA KASIH}

Program Studi Diploma III Kebidanan Politeknik Kesehatan Kementerian Kesehatan Ternate

\section{DAFTAR PUSTAKA}

Angraini FSD. 2014. BPM. Jurusan Kebidanan Poltekkes Kemenkes Malang.

Buku Acuan Pelatihan Klinik Asuhan Persalinan Normal. Asuhan Esensial, Pencegahan dan Penanggulangan Segera Komplikasi Persalinan dan Bayi Baru Lahir. 2008. Jakarta: Jaringan Nasional Pelatihan Klinik-Kesehatan Reproduksi Departemen Kesehatan Republik Indonesia (JNPK-KR).

Ismiyati. 2010. Faktor-Faktor yang Mempengaruhi Perilaku

Penerapan Asuhan Persalinan Normal pada Bidan di Wilayah Kerja Puskesmas Bambanglipuro Bantul. STIKES 'Aisyiyah Yogyakarta.

Khodijah, N. 2016. Psikologi pendidikan. Jakarta: PT Raja Grafindo Persada.

Kurniarum, A. 2016. Modul Bahan Ajar

Cetak Kebidanan. Asuhan

Kebidanan Persalinan dan Bayi Baru Lahir. Jakarta: Pusdik SDM Kesehatan Kementerian Kesehatan RI.

Maulana, Heri D.J. 2015. Promosi Kesehatan. Jakarta : Buku Kedokteran EGC

Mubarak, Iqbal W. 2016. Promosi Kesehatan untuk Kebidanan. Jakarta: Salemba Medika.

Nafiah U, dkk. Faktor yang Mempengaruhi Pelaksanaan Prosedur Pencegahan Infeksi pada Pertolongan Persalinan Normal di Kabupaten Pati (Studi pada Bidan Desa Pasca Pelatihan APN). 
Jurnal Manajemen Kesehatan Indonesia. 2014; 2(2).

Otto S. 2015. Hubungan Pelatihan Asuhan Persalinan Normal dengan Pengetahuan dan Keterampilan Bidan Desa dalam Pertolongan Persalinan di Kota Gorontalo. Kesehatan Ibu dan Anak, Dinas Kesehatan Provinsi Gorontalo.

Saputra L. 2014. Asuhan Kebidanan

Masa Persalinan Fisiologi dan Patologis. Tanggerang Selatan: Binarupa Ashsara Publisher.

Sari I. 2016. Hubungan antara Pengetahuan dan Pelatihan Asuhan Persalinan Normal (APN) dalam Pelaksanaan Standar Asuhan Persalinan Normal (APN). Prosiding Seminar Nasional dan Presentasi Hasil-Hasil Penelitian Pengabdian Masyarakat. ISBN 978-602-50798-0-1.

Soleh ES. Faktor-faktor yang berhubungan dengan pelaksanaan penerapan standar asuhan persalinan normal. Jurnal Ilmiah Universitas Batanghari Jambi. 2018; 18(3).

Wawan, A dan M. Dewi. 2016. Teori Pengukuran Pengetahuan, Sikap dan Perilaku Manusia. Yogyakarta: Nuha Medika.

Wiknjosastro, H. 2017. Ilmu Kebidanan. Jakarta: Yayasan Bina Pustaka Sarwono Prawirohardjo (YBPSP).

Yati. 2016. Buku Ajar Kebidanan Persalinan. Yogyakarta: Pustaka Rihama. 